\begin{tabular}{|c|c|c|c|}
\hline & Raw & & Lyophylized \\
\hline нм & $(n=22)$ & LTLT $(n=22)$ & $(n=18)$ \\
\hline Total Lipids (g/l) & $32,17^{*}$ & 31,31 & $30,87^{*}$ \\
\hline \multicolumn{4}{|l|}{ Fatty Acids\% } \\
\hline Myristic & 7.05 & 7.01 & 7.08 \\
\hline Palmitic & 23,38 & 23,25 & 23,49 \\
\hline Oleic & 30,79 & 31,24 & 31,14 \\
\hline Linoleic & 9,27 & 9,26 & 9,28 \\
\hline linolenic & 0,86 & 0,86 & 0,87 \\
\hline Arachidonic & 0,39 & 0,39 & 0,41 \\
\hline DHA & 0,24 & 0,24 & 0,26 \\
\hline Trans & $0.92^{*}$ & 0.91 & $1^{*}$ \\
\hline
\end{tabular}

Background Donor human milk (HM) was associated with slower growth in the early postnatal period. The macronutrient concentrations of HM could be influenced by the various processes used in human milk bank. The LTLT pasteurisation was known to slightly decrease protein and fat content of HMB. But The effect of the lyophilization was not described.

Aims To Compare the lipids compositions between raw/LTLT/ lyophilized HM.

Methods This is a monocentric of 22 batches independent prospective study on HM. After Folch extraction, Total fat was determined gravimetrically. The fatty acid (FA), after direct transesterification, were separated by capillary gas chromatography with BPX 70 column. Statistical analysis were: apparied t test and/or T of Wilcoxon.

Results

Conclusion Decrease of the fats was mainly observed after pasteurisation: difference $(\mathrm{d}=0.86 \mathrm{~g} / \mathrm{l})(\mathrm{p}=0.05$, after Bonferroni correction it is non significant); the lyophylization preserved almost total lipids after LTLT $(\mathrm{d}=0.26 \mathrm{~g} / \mathrm{l} \mathrm{NS})$. But the total effect of LTLT then lyophylization was a loss of $1.10 \mathrm{~g} / \mathrm{l}$ of total lipids and significant. There was no significant difference between each of the fatty acids with both processes. LTLT Pasteurisation is not an optimal decontaminating HM process and we have to develop new techniques.

\section{PO-0586 HYPERALIMENTATION AND PLASMA LEVELS OF AMINO ACIDS IN VERY PRETERM INFANTS DEPENDENT ON PARENTERAL NUTRITION}

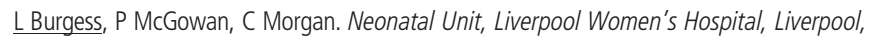
UK

\subsection{6/archdischild-2014-307384.1227}

Background The standardised, concentrated with added macronutrients parenteral (SCAMP) nutrition regimen provides hyperalimentation to very preterm infants (VPI). Current neonatal parenteral nutrition (PN) amino acid (AA) formulations predate recent recommended protein intakes. AA were categorised as essential, conditionally essential (in VPI) and non-essential. We hypothesised hyperalimentation would prevent low plasma levels of conditionally essential AA (CEAA).

Methods Infants ( $<1200 \mathrm{~g} ;<29$ weeks) were randomised to start SCAMP or remain on control before day 5. Daily parenteral (AA) and enteral protein intakes were calculated from daily nutritional data. Plasma AA levels were measured weekly in PNdependent infants by ion-exchange chromatography.

Results Infants were randomised to SCAMP $(\mathrm{n}=74)$ and control $(\mathrm{n}=76)$ groups. The mean difference $(95 \%$ confidence interval) in total protein intake $(\mathrm{g} / \mathrm{kg})$ was $8.7(6.0-11.5) \mathrm{d} 1-28$. All essential AAs (phenylalanine, lysine, valine, leucine, isoleucine, methionine, threonine, histidine and tryptophan) were within or above the reference range (RR) in both groups. Plasma arginine/cysteine levels (week 2) were below RR in both SCAMP $(n=45)$ and control $(n=62)$ infants (Table 1). Plasma cysteine levels (week 3) were below RR in both SCAMP ( $\mathrm{n}=39)$ and control $(n=36)$ infants.

Conclusion Despite hyperalimentation and increased protein intake, PN-dependent VPI remain biochemically deficient in some conditionally essential AAs.

\section{PO-0587 NUTRITIONAL MODIFICATION TO DECREASE THE EXTRAUTERINE GROWTH RESTRICTION IN VERY LOW BIRTH WEIGHT INFANTS}

M Chang, Y Lee. Pediatrics, Chungnam National University Hospital, Daejeon, Korea

10.1136/archdischild-2014-307384.1228

Background and aims Extrauterine growth restriction (EUGR; $\leq 10$ th percentile of intrauterine growth expected in accordance with the estimated gestational age) is a common problem in preterm infants. After birth, nutrition in preterm infant is dependent on externally administered nutrition and many preterm infants experience significant energy and nutrition deficits.

We modified our nutrition protocol and evaluated the incidence of EUGR and growth status.

Methods A prospective observational cohort study compared infants $\leq 1,500 \mathrm{~g}$ before $(\mathrm{n}=37)$ and after $(\mathrm{n}=50)$ modification of nutrition protocol. Modification included early starts of macronutrients with higher goal, earlier adding of human milk fortifier and higher goal of daily administered calorie. We evaluated demographics, enteral feeding, growth parameters, laboratory data and discharge outcomes. Differences in subgroups of infants $\leq 1,000 \mathrm{~g}$ and 1,000-1,500 $\mathrm{g}$ were also assessed.

Results Modified nutrition protocol reduced the incidence of EUGR at 36 weeks gestational age (GA) $(91.8 \%$ vs. $66.0 \%, \mathrm{p}=$ $0.005)$ and at discharge from NICU $(89.1 \%$ vs. $56.0 \%, \mathrm{p}=$ $0.001)$. EUGR was significantly reduced in infants $1,000-1,500$ $\mathrm{g}$ and trended toward reduction in infants $<1,000 \mathrm{~g}$. Height at

\begin{tabular}{|c|c|c|c|c|c|c|c|}
\hline & & Tyrosine & Cystine & Glutamine & Arginine & Proline & Glycine \\
\hline RR & & $33-75$ & $55-75$ & $325-800$ & $53-71$ & $141-245$ & $178-248$ \\
\hline Week 2 & $S$ & $59(34-85)$ & $26(16-33)$ & $495(387-560)$ & $41(25-54)$ & $395(326-462)^{a}$ & $388(339-452)$ \\
\hline Median (IQR) & C & $53(38-67)$ & $25(17-40)$ & $435(361-535)$ & $34(21-45)$ & $323(270-386)^{\mathrm{a}}$ & $392(316-466)$ \\
\hline Week 3 & $s$ & $89(57-107)$ & $36(30-49)$ & $544(401-617)$ & $52(39-69)$ & $369(306-452)^{b}$ & $434(405-566)$ \\
\hline Median (IQR) & $C$ & $56(47-86)$ & $36(24-41)$ & $494(413-562)$ & $47(29-57)$ & $296(255-366)^{b}$ & $447(339-528)$ \\
\hline
\end{tabular}


36 weeks GA increased significantly in infants 1,000-1,500 g and head circumference at 36 weeks GA increased significantly in all infants. No significant differences were seen in the rates of NEC, BPD, ROP, IVH and PVL.

Conclusions Modified nutritional protocol based on supplying the early aggressive macronutrients and higher calorie, can significantly reduce the incidence of EUGR in infants $\leq 1,500 \mathrm{~g}$ without any complications. We need further investigation to improve growth in infants $<1,000 \mathrm{~g}$.

\section{PO-0588 NEONATAL OUTCOMES OF VERY LOW BIRTH WEIGHT INFANTS WHO RECEIVED ENTERAL NUTRITION WITH AND WITHOUT OLIVE OIL SUPPORT: RANDOMISED CONTROLLED PILOT STUDY}

${ }^{1}$ A Ecevit, ${ }^{1}$ A Abbasoglu, ${ }^{1} U$ Tugcu, ${ }^{1} M$ Silahli, ${ }^{2} Y$ Laleli, 'A Tarcan. ${ }^{1}$ Pediatrics Neonatology, Baskent University Medical School, Ankara, Turkey; ${ }^{2}$ Specialized Chemistry Division, Duzen Laboratory, Ankara, Turkey

\subsection{6/archdischild-2014-307384.1229}

Background and aims Very low birth weight (VLBW) infants have a greater risk for the oxidative stress related diseases (OSRDs) like retinopathy of prematurity, bronchopulmonary dysplasia, periventricular leukomalacia and necrotizing enterocolitis. Naturel antioxidant activity of phenols, flavonoid and tocopherols in extra virgin olive oil (EVOO) may be preventive for the OSRDs. The purpose of conducting a randomised controlled pilot study is to compare the weight gaining, length of hospitalisation and the OSRDs of VLBW infants who received early enteral nurtition with and without EVOO support.

Methods VLBW newborns were divided into two groups in this pilot study. Group 1 received enteral nutrition and EVOO, Group 2 received only enteral nutrition. Nutritional analysis was undertaken for EVOO that was added as $0.5 \mathrm{ml} /$ day in $100 \mathrm{ml}$ enteral nutrition. Total parenteral nutrition (TPN) and minimal enteral nutrition was initiated both of two groups.

Results A total of 26 VLBW infants were divided into two groups (Group 1)(n=13) and (Group 2) $(\mathrm{n}=13)$ and assessed the birth weight: Group $1=1,329 \pm 35$ g, Group $2=1,276 \pm$ 32 g. gestational age: Group $1=31 \pm 2.79$, Group $2=29 \pm 2$ weeks. There was no significant difference between two groups for weight gaining, length of hospitalisation and the OSRDs.

Conclusions EVOO is very important natural antioxidant and anti-inflammatory nutrients for preterm infants particularly VLBW. A larger randomised controlled trials are needed to show the antioxidant and anti-inflammatory effects of olive oil for prevention of OSRDs in this high risk group.

\section{PO-0589 A MIXED BAG - HAS THE NATIONAL CONFIDENTIAL ENQUIRY INTO PATIENT OUTCOME AND DEATH (NCEPOD-REPORT, UK 2010) MADE A DIFFERENCE TO THE NUTRITION OF PRETERM INFANTS?}

${ }^{1} \mathrm{E}$ Chan, ${ }^{2} \mathrm{C}$ Smith, ${ }^{2} \mathrm{C}$ Davidson, ${ }^{3} \mathrm{R}$ Watkins, ${ }^{3} \mathrm{P}$ Amess, ${ }^{3} \mathrm{H}$ Rabe, ${ }^{3} \mathrm{JR}$ Fernandez Alvarez. ${ }^{1}$ Neonatology, Brighton and Sussex Medical School, Brighton, UK; ${ }^{2}$ Paediatric Dietetics, Brighton and Sussex University Hospitals NHS Trust, Brighton, UK; ${ }^{3}$ Neonatology, Brighton and Sussex University Hospitals NHS Trust, Brighton, UK

\subsection{6/archdischild-2014-307384.1230}

Background Early parenteral nutrition (PN) improves growth in preterm neonates. Good practice in $\mathrm{PN}$-care was identified in only $24 \%$ of the units in the NCEPOD-Report.

\begin{tabular}{|c|c|c|c|c|}
\hline & & BWz & $\mathrm{DWz}$ & TPN \\
\hline & 23-30GA & $-0.59(-1.02 / 0.07)$ & $-2.18(-2.57 /-1.59)$ & $12(7-18)$ \\
\hline \multirow[t]{2}{*}{2010} & $31-36 \mathrm{GA}$ & $-0.28(-1.11 / 0.36)$ & $-1.46(-1.95 /-0.95)$ & $0(0-1)$ \\
\hline & 23-30GA & $-0.32(-1.17 / 0.34)$ & $-1.4(-2.03 /-1.0)$ & $11(7-13)$ \\
\hline \multirow[t]{2}{*}{2011} & $31-36 \mathrm{GA}$ & $-0.4(-1.33 / 0.11)$ & $-1.92(-2.47 /-1.27)$ & $0(0-6)$ \\
\hline & 23-30GA & $-0.19(-0.9 /-0.06)$ & $-2.08(-2.69 /-1.28)$ & $8(1-10)$ \\
\hline \multirow[t]{2}{*}{2012} & $31-36 \mathrm{GA}$ & $-0.92(-1.1 / 0.07)$ & $-2.19(-2.63 /-1.44)$ & 10(3-11) \\
\hline & $23-30 \mathrm{GA}$ & $-0.38(-1.63 / 0.07)$ & $-2.04(-2.7 /-1.73)$ & $6(0-13)$ \\
\hline 2013 & $31-36 \mathrm{GA}$ & $-0.75(-1.52 /-0.27)$ & $-1.98(-2.69 /-1.36)$ & $8(4-10)$ \\
\hline Term & & $-1.53(-2.24 /-0.34)$ & $-1.63(-2.7 /-0.91)$ & \\
\hline
\end{tabular}

Aim To compare the growth of preterm infants since the NCEPOD-Report in relation to PN-use.

Methods Retrospective comparison of preterm infants cared for in a tertiary neonatal unit until 36 weeks gestational age (GA) between 2010-2013. Newborns were grouped by gestation (2330GA/31-36GA) and birth-year. Outcomes were z-scores for birthweight $(\mathrm{BWz})$, discharge-weight $(\mathrm{DWz})$ and length of $\mathrm{PN}$ in days (loPN). Outcomes were compared between years, within years and between GA-groups including >36GA-control-group. Data-presentation/-analysis: Median (interquartile-range); MannWhitney-U-Test/Kruskal-Wallis-Test ( $\mathrm{p}<0.05$ ).

Results 175 newborns recruited. No significant difference for $\mathrm{BWz}$ and $\mathrm{DWz}$ between years and for $\mathrm{BWz}$ and $\mathrm{DWz}$ between GA-groups within a year except for DWz 2010(p = 0.02). No significant difference for the same GA-group between years except for DWz 23-30GA(p = 0.04). No significant difference for loPN between years and between GA-groups within a year except for $2010(\mathrm{p}<0.0001)$ and $2011(\mathrm{p}<0.0001)$. No significant difference for the same GA-group between years except for $31-36 \mathrm{GA}(\mathrm{p}<0.0001)$.

Conclusion Growth in preterm infants assessed by difference in z-scores appears to have improved since 2010. This may be partly due to increased PN-use which although not significant shows a notable increase since the NCEPOD-Report.

\section{P0-0590 SUBSTANCE ABUSE DETERMINATION IN ALTERNATIVE MATRICES OF BREASTMILK DONORS}

${ }^{1} \mathrm{~N}$ García-Lara, ${ }^{2} \mathrm{D}$ Escuder-Vieco, ${ }^{3} \mathrm{O}$ García-Algar, ${ }^{4} \mathrm{E}$ Marchei, ${ }^{4} \mathrm{~S}$ Pichini, ${ }^{2}$ CR Pallás-Alonso. ${ }^{1}$ Neonatology, Hospital 12 de Octubre, Madrid, Spain; ${ }^{2}$ Neonatology, Hospital 12 de Octubre, Madrid, Spain; ${ }^{3}$ Unitat de Recerca Infància i Entorn, IMIM-Hospital Del Mar, Barcelona, Spain; ${ }^{4}$ Instituto Superiore di Sanita, Drug Control and Evaluation Department, Roma, Italy

\subsection{6/archdischild-2014-307384.1231}

Background and aims In human milk banks, the only available information regarding toxicological safety, is provided by donors in the screening questionnaire. A good agreement between donors' self-report and milk analysis for nicotine and illegal drug use (excluding caffeine) was reported. Determination of these substances in urine and hair samples may provide additional information.

Our main objetive was to determine drug abuse substances, nicotine and caffeine, in donors' breastmilk, urine and hair and compare the results to donors' answers in the screening questionnaire.

Methods 36 samples of breastmilk, urine and hair from 36 milk donors were collected. All donors completed a lifestyle questionnaire. A validated, reversed-phase liquid chromatography tandem 